\title{
'Every mother dances her baby': Contextually responsive narratives of early childhood care and education in Kenya and Uganda
}

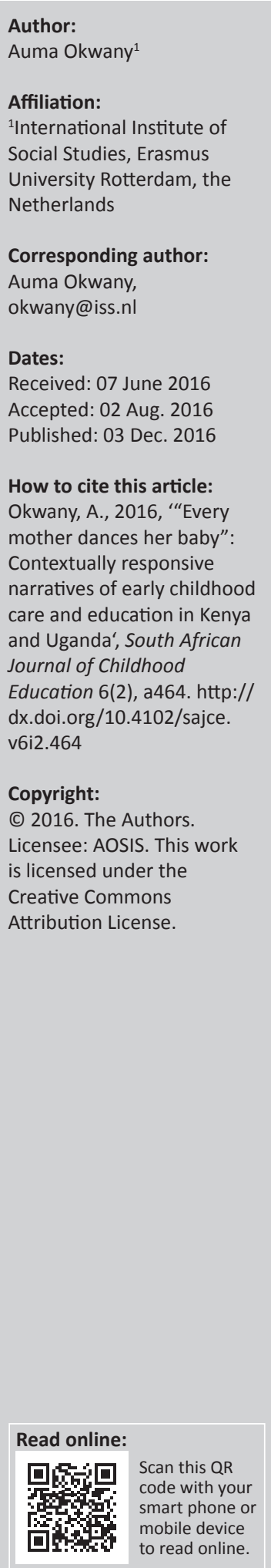

Despite major steps towards providing early childhood care and education (ECCE) services in Kenya and Uganda, access to responsive services is still out of reach for many young children, and where available, they are often out of touch with local realities. In this paper, I trouble the universalising and totalising tendencies of the dominant narrative of ECCE as a template of thought and action and highlight the role of indigenous knowledge as a critical but often missing link in ECCE policy and practice. I draw on the situated experiences of caregivers and local communities, which counter the dominant narrative and argue that culturally responsive ECCE requires contextually sensitive policy and programmes. Such policies should affirm and support the important role of local knowledge in the care and socialisation of young children. Policies should also recognise the informal resilient social protection system without obscuring the role of the state in addressing structural vulnerability.

\section{Introduction}

Childhood is a special stage in all cultures worldwide, and great care is exercised to invest distinctive values, beliefs and traditions that have been woven through time in the care and development of young children. This is done to ensure a smooth transition through the phases in the lifecycle into adulthood and intergenerationally. Childhood is thus socially constructed and lived in heterogeneous ways and as noted by Montgomery (2008:3), 'must be defined internally and in its own context'. This is because the interplay of variables, which shape childhood as well as the system of care and development, varies cross-culturally, by social group, gender and over time and space. This implies both a distinctiveness and diversity of socio-cultural contexts and circumstances.

Drawing on this distinctiveness of a peoples' indigenous way of knowing about childcare, the starting point for this paper is that, 'Every mother dances her baby'. The literal meaning of this proverb from the Bukusu community of Kenya is that regardless of a baby's size, every mother dances her baby, implying that the size of the baby does not hinder the parent/caregiver from nurturing it. The underlying meaning of the proverb is that all communities, families and households have distinct and valued indigenous ways of childcare, which have been passed down from one generation to another.

Indigenous knowledge (used interchangeably in this paper with local knowledge) refers to the wealth of internal resources within communities that have been developed over time, regenerated, appropriated and incorporated into hybrid coping strategies and social networks that form the central element of community capital (Okwany, Ngutuku \& Muhangi 2011:21). This knowledge is embedded in community practices, institutions, relationships and rituals. However, this diversity and difference is not always reflected in the decontextualised national policy and delivery systems often rooted in the dominant Euro-American narrative. My contention is consistent with Pence and Nsamenang (2008) who decry the pervasive, homogenous, Western-derived normative narrative of childhood, which obscures and even erodes diverse ethnicities, contexts (both material and social), and complexities of caregiving and of childhoods in Africa.

I draw on empirical evidence from a larger study, which examined the role of local knowledge in childcare in three communities in Kenya and Uganda (Okwany et al. 2011). The intergenerational study explored an array of rich resources for 'dancing' children, including socialisation and scaffolding strategies, proverbs and other forms of participatory pedagogies as well as a resilient social protection system rooted in reciprocity, mutuality and social justice. This is contrary to the dominant child 
development sensibilities that have failed to adequately recognise this rich contextual context in which parents and caregivers are the foundational carers and teachers.

The focus of this paper is on early childhood care and education (ECCE), which involves the holistic care and development of a child's physical, cognitive, emotional, social and moral wellbeing. In troubling the grand narrative of ECCE, I concur with Okwany and Ebrahim (2015) on the imperative of moving beyond the partiality of polarised narratives to the recognition of multi-centred in-between perspectives which converge or diverge beyond artificial global/local dichotomies. These local spaces are replete with practices, beliefs and interpretations of caregivers who are 'speaking subjects' and who articulate rich narratives about childhood and childcare. In providing these counter-narratives, the paper is an attempt, in Bhabha's terms, to 'rip through the sly civility of those grand narratives' of ECCE, exposing their epistemic and by extension practical and policy violence (1995:99).

The paper is organised as follows: After a brief contextual background, the discussion of methodology as well as an overview of the conceptual framing which guided data analysis is followed by an examination of the range of local assets in the care contexts including the situated experiences of communities and caregivers as indication of counternarratives that support care and stimulation of young children. I conclude by discussing implications for policy and practice, in affording children a contextually rooted early care and learning.

\section{Childcare contexts in Kenya and Uganda: Weak starting points}

Despite an expanded vision, domesticated rights instruments, ${ }^{1}$ comprehensive guidelines and policy frameworks for the care and well-being of young children in Kenya and Uganda, there are major gaps and inherent weaknesses in implementation that hinder universal state support of ECCE. The lack of universal social protection means that most young children are exposed to multiple and intersecting risks and vulnerabilities that profoundly affect their growth and development, as evidenced in poor child well-being indicators. Kenya has a comprehensive ECCE policy since 2006. In contrast, in Uganda, the draft integrated ECCE policy was officially adopted in 2013 and aims to address the fragmentation of services. Despite this integrated ECCE policy, the dominance of private provisioning in ECCE (over $80 \%$ ), lack of implementation oversight, incomplete and unreliable data represent major impediments to the promotion of holistic early childhood care and development. In Kenya, in the post-independence period, communities under the rallying call Harambee [pulling together]

1.This includes the United Nations Convention on the Rights of the Child and Genera Comment number 7, as well as the African Charter on the rights and Wellbeing of Children. The General Comment number 7 (GC7) focuses specific attention on implementing rights in the early childhood stage. In reviewing reports by states parties, the GC7 committee found very little information offered about early childhood, with comments limited mainly to child mortality, birth registration and health care. constructed over $80 \%$ of preschools in the country; however, education for 3- to 5-year-olds remains largely private or non-formal. Currently, there are indications of better management of ECCE within the context of the devolved governance system in Kenya, as exemplified by the county Early Childhood Development Bill 2014 and moving forward, county governments bearing the responsibility for hiring and management of teachers.

State's limited role in ECCE in both countries has created a developmental void that is filled by the private sector and non-state actors, as key providers of services for many young children. However, many of the ECCE programmes are in reality de facto pre-primary education centres that pay disproportionate attention to cognitive development via didactic learning methods and exam-oriented curricula including the promotion of English as the exclusive medium of communication and instruction (Okwany et al. 2011). ${ }^{2}$ This promotes what Choi (2006) and others refer to as the 'schoolification' of early childhood care and education pointing to the overall lack of creative stimulation, socialisation and play. The levying of fees in these centres means that access is restricted for economically vulnerable households raising equity concerns.

In both countries, there is also a troubling missing policy link for the critical under-3-year age category. Yet, households and communities make the most substantial investment (both human and financial) in the care and development of young children in this crucial period of birth to 3 years of age (Marfo et al. 2008). This is intensified in many contexts where serious economic inequalities and social exclusion challenges predominate. Such marginalisation places a disproportionate burden on local systems in the care and protection of young children while ignoring their central role in the micro-context of care. This not only makes many vulnerable communities feel disengaged with policy but also locates problems in the 'lack' in these spaces and on the caregivers' capabilities while skirting the critical role of the state in addressing structural issues of poverty. In this paper, I disrupt the dominant pervasive narrative that is implicated in this marginalisation by calling for a recognition of situated experiences. These diverse experiences and practices of 'dancing children' counter the dominant narrative and I argue provide critical starting points for ECCE policy interventions.

\section{Child care within the development niche framework}

Given the emphasis in this paper on the need for recognition of situated experiences in diverse cultural contexts, the theory that guided analysis is the development niche framework as expounded by Harkness and Super (1992, 1996) and Harkness et al. (2009). This theory illustrates the

2.This is in contradiction to language in education policy in Kenya, which requires learning in early childhood centres and the first 4 years of primary school to be conducted in local languages for contexts (e.g. rural areas) where the local language is the dominant first language. According to wa Thiong'o (1986) these are the effects of colonial language-in-education policies that were used as a means of spiritual of colonial language-in-education policies that were used as a means of spiritual
subjugation to separate children from their history and language, which were replaced by European history and language. 
diversity of ways in which children are nurtured in specific socio-cultural spheres. The development niche consists of three overlapping subsystems or spheres:

- The physical and social settings of daily life that involves examining the socio-physical environment where children live and develop and includes a consideration of how the spaces (home, community, day care centre etc.) are created, maintained and how they contribute to child development. This also involves initiating discussions with caregivers in these spaces including parents, care providers and exploring their psychology or ethnotheories (cultural beliefs and attitudes), which inform their caregiving and the (indigenous or hybrid) coping strategies they draw on to deal with risks and stress. The final sphere is the customs and practices of care which encompass inherited and adapted/hybridised ways of 'dancing children' including strategies for nurturing, stimulating, scaffolding, educating and protecting children.

- The spheres are replete with modes of knowledge, specific to each culture, that are articulated in a multiplicity of ways in recognition that 'every culture offers parental ethno theories' (Harkness et al. 2009; 2013; Super and Harkness 1986; 2009). I argue that in the distributed care system that prevails in the care contexts of the study communities, their narratives represent the scope of ethno-theories of caregiving for young children in these spaces. Importantly, the processes of care giving in the micro-contexts operate in harmony but are also influenced by the larger national and international culture and economy. In contexts of widespread vulnerability like Kenya and Uganda, it is important to view the role of caregivers within socio-cultural contexts in which poverty is a macro-structural issue. This reasoning and critique of the dominant narrative in ECCE is consistent with the critique of analyses of poverty by influential actors like the World Bank (Penn 2012) or academic sources like the prominent Lancet series (George 2010:15) that locate the problem on the deficits of poor children, their caregivers and their low-income 'unstimulating' homes while ignoring the deficits in the global and national structures that generate poverty, exclusion and inequality for poor households.

- The development niche framework is thus helpful for moving us beyond the dominant narrative and any artificial global local divides because it is useful for crosscultural examination of care, policy and practice, which are cultural products in all contexts.

\section{Leveraging the local in early childhood care and education research: A grounded inquiry}

The year-long study on which this paper is drawn was carried out in three communities in Kenya and Uganda among the Luo, Luhya and Baganda ethnic groups. The research methodology was participatory, utilising the appreciative enquiry approach. According to Bushe (1998), the key data collection innovation of appreciative inquiry is the gathering of people's stories which are collectively discussed in order to create new, generative ideas or images that aid in the developmental change for that specific community. The study aimed at enabling the participants to be both contributors to and users of knowledge while simultaneously producing knowledge that enabled the interrogation of the dominant narrative on child care (Okwany et al. 2011).

The major focus of the research was on shifts, changes and the dynamics of child caregiving contextually and over time. The study adopted an intergenerational enquiry (with three generations of parents) using mixed methods to trace the continuities and discontinuities of local ways of care and education of young children across three generations of caregivers. These included focus group discussions, interviews and life histories/lifelines. Multiple data collection sessions were carried out in different settings over the period of the study. Key informant interviews with selected participants within the study communities included church and community leaders, members of the council of elders and staff of state and non-state interventions. Interviews and discussions were shaped by the findings from the intergenerational inquiry. The mixed data sources enabled validation of research findings as a way of triangulating, contesting and interrogating commonly held beliefs and practices within the communities. The findings were further validated via local radio shows enabling dissemination of findings beyond study communities. Studio recordings of the findings were broadcast twice a week for 3 weeks culminating in live call-in shows. Radio and post-broadcast discussions emerged as a critical dialogue space enabling follow-up discussions and dissemination of findings beyond study communities.

The principal researchers played a facilitative role providing oversight to trained research assistants who were linguistic and cultural insiders and also residents within the study sites. Study participants were both contributors to and users of knowledge while simultaneously producing knowledge that enabled the interrogation of the dominant narrative on child care (Okwany et al. 2011). In addition to adhering to ethical principles of anonymity, confidentiality, informed consent and voluntary participation for study participants, we also maintained continuous reflexivity and progressive verification subjecting our role in the research to the same scrutiny as the data (Gullemin \& Gilliam 2004).

Data analysis and identification of themes was continuous and research actively involved participants in the collective process of 'progressive verification' (Billson 1991), which enabled triangulation and validation of data. As a grounded engaged enquiry (Milan 2010:856), this methodology enabled reflexivity of the researcher/participants in the dialogical process that was central to the data collection process. By taking into account caregivers' ethno-theories within their settings and listening to their ways of caregiving, they were validated as 'speaking subjects'. 


\section{Decentring grand narratives in early childhood care and education: Whose early childhood care and education?}

Paraphrasing Gielen and Roopnarine (2004:xv), it is fair to say that the pervasive grand narrative of childhood and childcare 'In the face of ever-accelerating global change ... now appears too static, too homogenous, too Euro-American, too middle-class, too male, and too monocultural'.

Africa's ECCE programming is mounted mainly on questionably extrapolated evidence (Penn 2005). This dominant narrative as the standard template for ECCE policy and practice revolves around giving children a 'good start'. The good start is often out of touch with local realities because it has been constructed from outside (Euro-American) and implemented from the top (state-led and based on assumed and not articulated needs). A critical question that remains unanswered is whose ECCE and whose good start?

For too long, the story of children in Africa has been told by those in positions of power, and in this naming, local ways of childcare have been abstracted from context and some of them seen as gothic and deficient when measured against dominant norms (Okwany et al. 2011:131). Pence (2013) and Penn (2012) remind us that the science of child development has roots in a Western 'civilising' imperative based on an image of deficiency. Such framing underpins the pathologisation and misrepresentation of African childhoods and childcare within the dominant narrative of ECCE. This (mis)framing of African childhood as victims of 'retrogressive' culture and deficient care contexts underlies the problematic 'salvation interventions' in discourse, policy and practice. Imported ECCE models in Africa fail to take into consideration the context or as noted by Dahlberg, Moss and Pence (2007:149): 'the theories and concepts through which the owners of the culture see their cultural world'. The ubiquity of this universal narrative means that the needs of children and communities are discursively constructed often portraying them as passive recipients of aid or assistance. The findings present examples and counter-narratives which show that far from being passive recipients of assistance, communities, who often receive inadequate state social services, draw on local resources to mitigate risk and provide care in the micro-context.

\section{Indigenous knowledge in early childhood care and education}

Study findings affirm that indigenous knowledge is a critical component of community coping strategies utilised to meet the needs of local communities in addition to, or in the absence of state-led interventions. The research recognised the importance of both assessing these ways of knowing and doing as a possible router to eliminating harmful practices that violate rights, while crowding in and synergising positive practices with the local continuum of social services as a pathway to inclusive ECCE policy and practice.

The examples profiled in this paper encapsulate the adaptive capabilities of household and community structures highlighting elements of community regeneration and strength that provide critical starting points and avenues for contextually responsive policy and interventions. It is noteworthy that some of these communities are coping without external support, thus dislodging the dominant discursive construction that global knowledge on child care is always a prerequisite for strengthening child care environments.

These counter-narratives point to a need for a shift from problematising the needs of families in deprived locales to a focus on how community 'assets' in child care can be leveraged and synergised with current interventions and resources. The central role of the state as the final arbiter for addressing structural poverty must be underscored and I argue that crowding in these rich local strategies controlled by community members would enable what Sutton (2001) calls a democratisation of policy-making practices to work from the broadest and deepest possible involvement of the beneficiaries of development efforts in all stages.

\section{The village still raises the child: Critical starting points of childcare}

Research findings support evidence that households and communities in a child's microenvironment remain the most critical safety nets even in contexts where shocks such as HIV and/or AIDS, conflict and structural exclusion have strained family and community capital (Irwin, Adams \& Winter 2009; Richter, Foster \& Sherr 2006; Swadener, Kabiru \& Njenga 1995). This contradicts proponents of the social rupture thesis who maintain that in the context of HIV and/or AIDS as a shock in the care system, community support structures have ruptured and are no longer able to provide care and protection to vulnerable children. An increasing number of studies have opposed this simplistic reading of community capacity noting that household and community support is stretched and overextended making it a 'safety net with holes' but one which remains resilient.

Indeed, communities are going through processes of social rebonding and reconfiguration in which new forms of adaptive strategies are emerging, albeit with varied degrees of success (Abebe \& Aase 2007; Madhavan 2004; Nyambedha, Wandibba \& Aagaard-Hansen 2003). This highlights the central role of the state in addressing structural ill-being. The local social networks and support groups profiled in this paper are utilising innovative strategies to assist vulnerable children as well as vulnerable caregivers within their communities. The failure of the state to crowd in these adaptive strategies means that though these care structures are adaptive and resilient, they are stretched and overburdened. 


\section{Brooding on care: 'Spreading wings over vulnerable children'}

The efforts of a women's group within the network of the community-based umbrella organisation, Kinda Women for Development in Siaya county in Kenya is illustrative. Their implementation strategy is focused on leveraging indigenous knowledge for the care and protection of children and for their own livelihood enhancement. The group came into being as a response to the emergence of the first child-headed homestead identified in the village and they moved to establish an early childhood centre within this home. Their activities were therefore conducted from the child-headed home, thus 'spreading their wings' over the orphaned children by providing material, emotional and psychosocial support. This not only helped to protect, nurture and stimulate these children, but catered to all young children in the community in a truly inclusive way.

Group activities have grown to revolve around a multifaceted network of activities viz., improving physical and social environments for vulnerable children, improving child nutrition, health and stimulation, sustaining a communitybased child monitoring and protective system, as well as livelihood enhancement and advocacy activities. This has enhanced community cohesion and greatly reduced stigma within the community as the services target all children. The group currently supports a vibrant ECCE programme that works with caregivers and community groups to promote holistic child well-being. Many of the initial beneficiaries have completed high school and are adults with families of their own.

Through the monitoring system, community-derived vulnerability indicators reveal pathways for improved child well-being, including improved nutrition, health and health seeking, rates of immunisation and marked improvements in child vibrancy (active and alert) for targeted children. These children are stimulated and receive nutritious meals at the ECCE centres, which also have adjoining demonstration gardens and sessions where health and nutrition information including indigenous food preparation and preservation are conducted. This provides space for addressing the needs of young children and pregnant and lactating mothers. As noted by a teacher at the centre:

'Parents and caregivers' contributions are critical and include inkind transfers like grains for making porridge and nutritious snacks, as well as labor in the school garden or cutting grass and helping us make learning and play materials' using local resources.'

The organisations' achievements have boosted group members' self-confidence to organise and seek support from local government. The ECCE centres are also linked with the local-level Centre for Early Childhood Education. The concept of harnessing local resources for early childhood development is a critical mobilising point with more community members at the core of the implementation enthusiastic about networking and sharing ideas.

\section{'Home-Grown' resources to support child well-being}

In Uganda, a local non-governmental organisation, Health Child, works with households in economically deprived islands (landing and fishing sites) in Jinja and Wakiso districts. Project activities centre around leveraging community resources through a project titled, 'Home Grown Resources for the Care and Protection of Young Children'. 'Home grown' is seen in two distinct ways: It refers to the range of indigenous knowledge and resources that community members have and can draw upon to improve well-being. In the project context with no farmland, homegrown also refers quite literally, to the micro-garden project initiated to provide fresh vegetables and produce. These are grown in a range of containers including sacks, old tires, in front/backyards, roofs and vacant spaces. The project also uses indigenous organic fertiliser and pesticide. This initiative has improved household and community food security, nutrition and household income through sale of surplus produce.

Communities' active role in implementing activities has increased ownership of the project. ECCE centres have been established in spaces and structures donated by community members. Learning and play materials are developed by parents and children using locally available materials. This has promoted creativity and boosted learning as well as parental involvement in learning. Indigenous pedagogical strategies such as songs, storytelling and local games (collected from the community) are at the centre of stimulation and early learning with the active involvement of parents and caregivers. The stories and songs are part of the repertoire of community resources.

Older women play a key role in strengthening community and household capacity including socialisation and providing generational continuity by mentoring young mothers in indigenous food preparation techniques and nutrition. Support and promotion of traditional birth attendants and indigenous medicine has contributed to improving the health of expectant mothers, ensuring safe delivery and improving the health of young children. Indigenous techniques for growth monitoring such as the use of waist and armbands have been incorporated into a responsive blended system to monitor the growth and development of young children. The project also supports traditional birth attendants and traditional healers to complement constrained state health services for maternal and child health. This linkage with local health facilities ensures synergy and a continuum of healthcare.

A key feature of this project is the revival of communitydriven social mobilisation and communal sanctions where community members have established by-laws for ensuring good sanitation and hygiene. Each household constructs sanitary facilities like pit latrines, bathrooms and dish-drying racks, failure of which results in a monetary fine imposed on defaulting households. The fine paid to the village 
health and sanitation committee is then used to construct these facilities for defaulting households. These civic-driven initiatives have facilitated dialogue in the community about how best to improve the physical and social childcare context and how to claim services from the state.

\section{Men also 'dance' children}

The adaptability and resilience of the informal safety net in childcare is illustrated by the evolving role of men in the predominantly feminised care spaces of ECCE. Findings revealed a small but increasing number of men who were actively engaged in child caregiving. Lower Ambira Community Child Development Program in Kenya actively kindled the interrogation of gendered constructions of childcare by stimulating increased involvement of fathers in 'dancing' young children. Older men are mentoring young fathers on responsible fatherhood, and they are also taking an active role in advocacy against domestic violence thus engaging with and working to transform aggressive masculinity. The notion of social fatherhood has also been strengthened and includes men (not just women) fostering orphans thus enabling a richer support system for child caregiving. Men are also supporting nurturing, play and stimulation of children at home and in centres and are truly, 'holding up the other half of the child's sky' (Richter \& Morrel 2008:151).

\section{'Getting by': The lack of state impact in vulnerable communities}

Serious economic inequalities and social exclusion challenges remain entrenched for many young children in the Global South (Woodhead 2006). Within the context of widespread economic insecurity and limited state outreach in Kenya and Uganda, the community efforts and narratives presented in this paper, offer critical support for child care through 'horizontal philanthropy' and are often the safety nets of first or only resort for many vulnerable households and communities. However, I concur with Okwany and Ngutuku (2016) who assert that it is too much for the state to expect marginalised communities to continue assisting each other and not receive services as a right and they note that the social contract between citizens and the state is weak because many people do not feel the impact of the state in their lives. Indeed these informal social protection services are largely preventive and palliative helping people to 'get by' on their own strength and ingenuity with no significant change in structural inequalities and poverty underpinning child vulnerability (ibid.). In arguing thus, I am heeding the caution by Penn (2012) that widespread poverty, inadequate education and poor health care are structural issues that should be directly addressed by the government in consultation with civil society.

\section{Contextualising childhood and child rights}

As foundational spaces of care, the micro-context offers critical starting points for childcare and stimulation. In all the study communities, childhood was conceptualised to start at conception or in the words of Jeni, a second-generation study participant, 'when the menstrual flow stops'. The benefits of having children also came with great responsibility and childhood was viewed as requiring special nurturing starting at conception. The social construction of childhood codified in proverbs, embodies local conceptions of childhood and care. A proverb from the Bukusu ethnic group holds that, 'If you want to have a banana plantation, you must take care of the single banana plant'. This was interpreted to mean that parents and caregivers were obligated to nurture and protect the whole child to ensure holistic development and thriving of all children and the community. A Luganda proverb Mwana mugimu ava ku ngozi was interpreted to mean that care for the holistic development of the child starts in the cradle (including the prenatal stage).

The range of proverbs collected and analysed encapsulate indigenous constructions of children's rights. If as the Bukusu proverb declares, 'every mother dances her baby', it is erroneous to view rights as a 'modern' phenomenon to be 'taught' to communities. A proverb from the Luo ethnic group which illustrates the embedment of a rights orientation contends: nyathi ok ma ng'etane, 'A child must not be deprived of their play seed'. An iterative discussion and analysis of this proverb inter and intra-generationally and also validated with a cultural historian revealed that it referred to the bundle of rights to which a child is entitled and which must be upheld and protected. This includes the right to care, protection, play, security and to a name that enhanced one's cultural identity. Children's right to ownership for instance was protected and discussions revealed that nobody was allowed to take from a child what was given to them because 'the giving and receiving bestowed rightful ownership'. This ranged from ownership of seemingly mundane things like an animal or their own small part of the garden to tend to more substantive things like identity, belonging and security. This cultural entitlement to rights provides a critical pathway for meaningful engagement with communities. It stands in sharp contrast with current processes of advocating and promoting children's rights which according to Norman (2014) have often targeted children and marginalised caregivers and thus lacked their 'buy in' leaving behind a landscape of frustrated adults and tension between adults and children.

\section{The silenced narrative of participation and resilience building}

The assertion that children, in African settings, are to be seen and not to be heard has been a taken for granted doxa which has escaped scrutiny and rarely has it been in the interests of communities. During a focus group discussion with firstgeneration participants in Kenya, they rejected this contention and pointed to children's critical role in everyday family routines as competent, active, individual, members and contributors to the functioning of households with a voice. Child participation was not seen as giving children 'platforms' to talk but was closely related their active participation in everyday family and community routines. Participation was thus actively promoted by inculcating responsibility and 
building resilience while enhancing self-esteem through what Nsamenang and Lo-oh (2009) call 'responsibilisation'. However, there is a disconnect with some of the current initiatives which have failed to locate this resilience building aspect of children's participation in community life and have instead erroneously conflated resilience building activities with exploitative child labour.

Another important aspect of participatory learning is peer education and the place, action and voice of older children, which is central to supporting young children's stimulation and development of norms. Nsamenang (2008) draws attention to the critical role of older siblings in the care of young children within the distributed social network of caregiving. Similarly, in their qualitative child-to-child study, James and Ebrahim (2012) highlight the central role of older siblings in the distributed caregiving system and in social cohesion by showing how older children created fun-filled creative learning and mentoring opportunities. However, the place of siblings in caregiving has not been well researched and remains a largely uncharted development niche.

\section{The unwritten everyday curriculum}

Study findings revealed that indigenous forms of pedagogy provide valuable lessons for refuting the dominant restrictive ideology of education as the formal/institutionalised model which takes place in a designated space (school) and knowledge as the privilege of the expert (teacher). Indigenous pedagogy in contrast is not didactic but expansive and participatory. This is consistent with the assertion by Pence and Nsamenang (2008) that:

in the indigenous cultures of sub-Saharan Africa, educational ideas and practices are embedded in family traditions, daily routines, and social and community life. Kinship, beginning with the family, is the socio-affective base from which individuals develop a sense of selfhood and personal identity. It is from the caring and generative role of the family that children begin to learn about moral life, participative skills, social values, and ways of the world. (p. 32)

Discussions, especially with first- and second-generation parents, reveal that learning was conceived as a continuous activity that began in infancy and extended throughout childhood encompassing interaction with multiple caregivers and extended family, as well as everyday routines through learning by doing. These findings are consistent with the assertion by Nsamenang and Lo-oh (2009:399) that African cultures in some way transcend Vygotsky because they prepare children from an early age to seek out others, extract 'intelligences' and define self within a dense sociological field of keen, siblings, peers / friends and neighbours. Indeed according to Moumouni (1968) cited in Nsamenang (2009), in much of Africa, an unwritten curriculum is wedged into the daily routines of family and society and sequenced to fit into the developmental stages of the school of life.
The participatory nature of this indigenous pedagogy has major implications for active 'playful' learning in ECCE and the need to view ECCE beyond formal centres including strengthening the role of parents/caregivers and community members as 'foundational teachers' and a critical part of a child's everyday learning environment. As noted by Nsamenang and Pence (2008:41), an inclusive approach to ECCE programmes could provide more affordable services to more children in different locales if it included the following: self-regulation, self-education, child-to-child stimulation and mentoring within a peer culture. Additionally, they point to an integrated system of diversity when they note that it would dispense ECCE services differently, with different training and accreditation criteria.

Participatory pedagogy provides pathways to change decontextualised learning that characterises education in formal centres and to counter the pervasive 'schoolification' of early learning in these spaces. This requires embedding appropriate participatory learning and pedagogical principles into early childhood development policy and programmes and strengthening the role of parents/caregivers and community members as a critical part of a child's everyday learning environment. This is consistent with the assertion by Barry and Zeitlin (2011) and Serpell (2011) that the African indigenous curriculum is geared towards stimulating young children through a range of strategies that include infant body massage to promote growth and motor competencies; strengthening children's socio-adaptive, linguistic and affective skills and promoting contextual measures of intelligence which blend cognitive alacrity and social responsibility.

Interventions profiled in this paper support the promotion of a range of socialisation strategies including participatory pedagogical tools and active involvement of parents and caregivers to sustain learning. Indeed, Zeitlin and Barry (2008) show the importance of fusing local knowledge with more global understanding of child development in their a programme for curricular change in Senegal that built on traditional ideas about teaching and learning in infancy and early childhood, adapting them through group discussion to meet existing educational demands. This heeds to the caution by Marfo et al. (2008) that:

we need to be highly circumspect about developmental stimulation in terms of the lessons we choose to draw from traditions, practices and knowledge bases accumulated from other parts of the world. (p. 205)

I concur and argue that confronting the myriad challenges that impede learning systems will only be transformative if a shift is made away from a conception of education that is defined solely by formal schooling and driven by a decontextualised knowledge base. The search for long-lasting solutions and sustainable development in Africa must include a widening of the learning base and drawing from structures that extend to the rediscovery of suppressed traditional and local resources (Adala \& Okwany 2009). 


\section{'Re-membering' the local in early childhood care and education policy and practice}

The findings highlighted in this paper provide valuable insights on local knowledge and practice that have a significant bearing on the health, social, emotional and cognitive development of children. 'Re-membering' refers to knowledge that must be put back together from dismembered fragments held by individuals in different groups, who have had their traditional ways of knowing held in contempt and marginalised or disallowed. Therefore, re-membering IKS in ECCE implies enabling local communities as noted by Myers (1999) to appreciate their past as a departure point to any new story on child development.

Most endeavours to universalise ECCE have focused on empowering communities without focusing on their resources and as Cooke and Kothari (2001) argue, the discourse of participatory development as used by many development agencies has 'tyrannical potential' that facilitates unequal power relations. Empowerment as used by these agencies comes with a significant loss of freedom to the communities they purport to empower. ECCE programmes have disempowered parents as primary educators and caregivers of children and ignored the fact that 'every mother dances her baby' (from the perspective of Bukusu ontology). Indeed, because of the ubiquity of the dominant narrative, most projects have tended to discursively construct the needs of children and communities and have often portrayed them as passive recipients. These interventions have also tended to focus disproportionate attention on the needs of the communities and on what they lack while ignoring available assets and resources that can be harnessed for potentially more inclusive childcare. In this process, they have also often obscured the role of the state in addressing structural vulnerability.

The significance of this paper for responsive ECCE is seen within the context of the importance of cultural specificity in ECCE. Responsive ECCE requires some major shifts. There is a need for a shift from the dominant practice of privileging expert knowledge and resources to leveraging local knowledge and fusing them with institutional ECCE knowledge and resources. This will strengthen the capacity of community members' and caregivers (the foundational teachers and 'educarers') to play an active role in efforts to make ECCE inclusive. A responsive policy and practice is also selfinterrogating and focuses on asking the critical question Whose ECCE? Whose good start? This is because the prevailing actions in ECCE have been about ensuring a good start for children. However, this start as well as the overall conception of ECCE is often out of touch with local realities because it has been constructed from outside, implemented from the top and is often based on assumed needs.

In interrogating this discursively constructed grand narrative of ECCE, I argue for multiple perspectives as a critical pathway to ensure active community involvement in ECCE. Calling for a contextual perspective in policies does not mean advocating for an 'either' 'or' perspective but for working 'within and against' the grand narrative. These discussions affirm that caregiving is informed by local culture, embedded in personal and indigenous knowledge. This local knowledge which is dynamic and emphasises change and continuity is utilised to meet the needs of communities to supplement or compensate for the inadequacies of state interventions. By pointing to this important role of community assets and locally appropriate scaffolding, I argue for integrated ECCE that includes health, social protection and psychosocial support as well as a maximalist conception of learning which starts at home in the early years and extends to lifelong learning beyond formal education throughput the lifecycle. These are starting points for enabling active community voice and action in policy in holding the state to account and ensuring more democratic processes of engagement.

\section{Conclusion: Rescuing early childhood care and education from the single narrative}

For too long, the story of children in Africa and how they grow and develop has been told by those in positions of power and in ways that disempower communities. This has led to cultural incapacity captured in the Swahili proverb, Mwacha mila ni mtumwa. A person who abandons their culture is a slave (to the foreign culture). This is an exhortation to learn from other cultures while being rooted in and strengthening one's own. By presenting the range of indigenous resources including an informal social safety net system that is strained yet adaptive and resilient, I have argued in this paper for a recognition of the central role of indigenous knowledge as a starting point in the care and development of young children. However, this knowledge has been 'dismembered' and relegated to the periphery of the dominant child development narrative and constrained by state-limited reach in tackling structural vulnerability.

Additionally, investigative methodologies in this area fail to nuance child care contexts. The arguments in this paper and in the larger study add voice to the call by Odora-Hoppers (2010) for 'repositioning objects' of research and I argue for the need to question the power relations that are embedded in ways of knowing in early childhood development research. Through reflexive, participatory, research praxis, the counternarratives presented in this paper discount the widely held marginalising notions in dominant research narratives and highlight the importance of providing space for the 'other' in knowledge creation and contribution. Communities, such as those in the study context, are not mere objects of research in child development, but are in their own right, authorities in this epistemological domain. Through participation in the research, they were 'speaking subjects' their voice and action in policy amplified and their narratives countering claims based on their knowledge and practice in child development and child rights. 
The discussion in this paper contributes to the growing discourse on the need to develop culturally sensitive approaches to care, learning and socialisation in recognition as noted by Gottlieb (2004:xvi) that, 'babies are deeply constructed by culture'. There is need for responsive evidence-based research into forms of ECCE policy that is inclusive of children and caregivers as speaking subjects. The goal, as noted by Nsamenang and Pence (2008:36), should be to instigate a generative process by which Africa can gain by engaging in a bridging project of reviewing and renewing its long-established systems of education in the cause of promoting policy and interventions that are respectful of families and societies and their ability to transfer knowledge, values and skills across generations.

\section{Acknowledgements Competing interests}

The author declares that she has no financial or personal relationships which may have inappropriately influenced her in writing this article.

\section{References}

Abebe, T. \& Aase, A., 2007, 'Children, aids and the politics of orphan care in Ethiopia: The extended family revisited', Social Science \& Medicine 64, 2058-2069. http://dx.doi.org/10.1016/j.socscimed.2007.02.004

Adala, A. \& Okwany, A., 2009, 'From schooling for some to lifelong learning for all: A paradigm shift for education and development in Africa', in M. Amutabi \&
M. Okech (eds.), Studies in lifelong learning in Africa: From ethnic traditions to M. Okech (eds.), Studies in lifelong learning in Africa: From
technological innovations, Edwin Mellen Press, New York.

Ainsworth, M. \& Filmer, D., 2002, Poverty, AIDS and children's schooling: A targeting dilemma, World Bank Policy Research Working Paper 2885, World Bank, Washington, DC

Barry, O. \& Zeitlin, M., 2011, 'Senegal's traditional and modern curriculum for children aged 0-3 years', in A.B. Nsamenang \& M.S. Tchombe (eds.), Handbook of African educational theories and practices: A generative teacher education curriculum 123-137, Presses Universitaires d'Afrique, Yaounde., Cameroon.

Bhabha, H., 1995, 'In the spirit of calm violence', in G. Prakash (ed.), After colonialism Imperial histories and post-colonial displacements, pp. 326-346, Princeton University Press, Princeton, NJ.

Billson, J.M., 1991, 'The progressive verification method: Toward a feminist methodology for studying women cross-culturally', Women's Studies International Forum 14(3), 201-215. http://dx.doi.org/10.1016/0277-5395(91)90111-T

Bushe, G.R., 1998, 'Appreciative inquiry in teams', The Organization Development Journal 16(3), 41-50.

Choi, S., 2006, 'Bite off only as much as you can chew': Gambia's policy of early childhood development, Policy brief on early childhood development. No 34, UNESCO, Paris.

Cooke, B. \& Kothari, U. (eds.), 2001, Participation: The new tyranny? Zed Press, London.

Dahlberg, G., Moss, P. \& Pence, A.R., 2007, Beyond quality in early childhood education and care: Languages of evaluation, 2 nd edn., Routledge Falmer, London.

George, S., 2010, 'Wasted childhoods? Beyond the pathologization of poor children and their families', in The doors of perception: Viewing anthropology through the eyes of children, Department of Social and Cultural Anthropology, Vrije Uyes of children, Department of Social and 1 .

Gielen, U.P. \& Roopnarine, J.L. (eds.), 2004, Childhood and adolescence: Cross cultural perspectives and applications, Praeger. Praeger, Westport, CT.

Gottlieb, A., 2004, The after-life is where we come from: The culture of infancy in West Africa, University of Chicago Press, Chicago, IL.

Gullemin, M. \& Gilliam, L., 2004, 'Ethics, reflexivity, and "ethically important moments in research"', Qualitative Inquiry 10(2), 261-280. http://dx.doi.org/10.1177/ 1077800403262360

Harkness, S. \& Super, C.M., 1992, 'The developmental niche: A theoretical framework for analyzing the household production of health', Social Science \& Medicine 38(2), 217-226. http://dx.doi.org/10.1016/0277-9536(94)90391-3

Harkness, S. \& Super, C.M. (eds.), 1996, Parents' cultural belief systems: Their origins, expressions, and consequences, Guilford, New York.

Harkness, S., Super, C.M., Barry, O., Zeitlin, M. \& Long J., 2009, 'Assessing the environmen of children's learning: The developmental niche in Africa', in E. Grigorenko (ed.) Multicultural psychoeducational assessment, pp. 133-155, Springer, New York.

Harkness, S., Super, C.M., Mavridis, C.J., Barry, O. \& Zeitlin M., 2013, 'Culture and early childhood development', in P. Rebello Britto, P. Engle \& C. Harkness (eds.) Handbook of early childhood development research and its impact on globa policy, 142-160, Oxford University Press, Oxford.
Irwin, A., Adams, A. \& Winter, A., 2009, Home truths: Facing the facts on children, AIDS, and poverty - Final report of the joint learning initiative on children and HIV/ AIDS, Joint Learning Initiative on Children and HIV/AIDS (JLICA), Boston, MA.

James, M. \& Ebrahim, H., 2012, 'Pedagogic activities for early education in a child-tochild programme in South Africa', in T. Papatheodorou \& J. Moyles (eds.), Crosscultural perspectives on early childhood, Routledge, London.

Madhavan, S., 2004, 'Fosterage patterns in the age of AIDS: Continuity and change', Social Science \& Medicine 58(7), 1443-1454. http://dx.doi.org/10.1016/S0277 9536(03)00341-1

Marfo, K., Biersteker, L., Sagnia, J. \& Kabiru, M., 2008, 'Grounding in community development and capacity building: Responding to the challenge of meeting the needs of children under 3 in Africa', in M. Garcia, A. Pence, \& J.L. Evans (eds.), Africa's future, Africa's challenges: Early childhood development in sub-Saharan Africa, World Bank Publications, Washington, DC.

Milan, S., 2010, 'Toward an epistemology of engaged research', International Journa of Communication 4, Feature 856-858.

Montgomery, H., 2008, An introduction to childhood: Anthropological perspectives on children's lives, Wiley-Blackwell, Oxford.

Myers, B.L., 1999, Walking with the poor: Principles of transformational development, Orbis Books, Maryknoll, NY.

Norman, A., 2014, 'Children's rights in the times of AIDS in KwaZulu Natal South Africa', in A.T.D. Imoh \& N. Ansell (eds.), Children's lives in an era of children's rights: The progress of the convention on the rights of the child in Africa, Routledge., London.

Nsamenang, A.B., 2008, '(Mis) Understanding ECD in Africa: The force of local and global motives', in M. Garcia, A. Pence \& J. Evans (eds.), Africa's future, Africa's global motives, in M. Garcia, A. Pence \& J.
challenge, The World Bank, Washington, DC.

Nsamenang, A.B., 2009, 'A critical peek at early childhood and care in Africa', Child Health and Education 1(1), 44-55.

Nsamenang, A.B. \& Lo-oh, J., 2009, 'Afrique Noire', in M. Borstein (ed.), Handbook of cross-cultural development, pp. 383-407, Taylor \& Francis., New York.

Nyambedha, E.O., Wandibba, S. \& Aagaard-Hansen, J., 2003, 'Changing patterns of orphan care due to the HIV epidemic in western Kenya', Social Science \& Medicine 57(2), 301-311. http://dx.doi.org/10.1016/S0277-9536(02)00359-3

Odora Hoppers, C., 2010, 'Renegotiating agency in knowledge production, innovation and Africa's development in the context of the triage society', Critical Literacy: Theories and Practices 4(1), 78-94.

Okwany, A. \& Ebrahim, H., 2015, 'Rethinking epistemology and methodology in early childhood research in Africa', in A. Farrell, S.L. Kagan \& K. Tisdall (eds.), Handbook of early childhood research, Sage, London.

Okwany, A. \& Ngutuku, E., 2016, 'Social protection and citizenship rights of vulnerable children: A perspective on interventions by non-state actors' in Western Kenya', N. Awortwi \& W. Gregor (eds.), Governance below the state: Social protection by non-state actors in Africa, Palgrave Macmillan., London.

Okwany, A., Ngutuku, E. \& Muhangi, A., 2011, The role of local knowledge and culture in child care in Africa: A sociological study of several ethnic groups in Kenya and Uganda, Edwin Mellen Press, New York.

Pence, A., 2013, 'Voices less heard: The importance of critical and "indigenous" perspectives', in P. Rebello Britto, P. Engle \& C. Harkness (eds.), Handbook of early
childhood development research and its impact on global policy, Oxford University Press., Oxford.

Pence, A. \& Nsamenang, B., 2008, A case for early childhood development in Sub-Sahara Africa, Working paper 51, Bernard van Leer Foundation., The Hague, the Netherlands.

Penn, H., 2005, Unequal childhoods: Young children's lives in poor countries, Routledge, London.

Penn, H., 2012, 'The rhetoric and realities of early childhood programmes promoted by the World Bank', in A. Twum Danso-Imoh \& R. Ames (eds.), Childhood at the intersection of the local and global, Palgrave MacMillan., London.

Richter, L., Foster, G. \& Sherr, L., 2006, Where the heart is: Meeting the psychosocia needs of young children in the context of HIV/AIDS, Bernard van Leer Foundation, The Hague, the Netherlands.

Richter, L. \& Morrel, R., 2008, 'Fathering: The role of men in raising children in Africa Holding up the other half of the sky', in M. Garcia, A. Pence \& J. Evans (eds.), Africa's future, Africa's challenge: Early childhood care and development in subSaharan Africa, World Bank, Washington, DC.

Serpell, R., 2011, 'Social responsibility as a dimension of intelligence and an educational goal: Insights from programmatic research in African society', Child Development Perspectives 5(2), 126-133.

Super, C.M. \& Harkness, S., 1986, 'The developmental niche: A conceptualization at the interface of child and culture', International Journal of Behavioral Developmen 9, 545-569. http://dx.doi.org/10.1177/016502548600900409

Super, C. M. \& Harkness, S., 2009, 'The developmental niche of the newborn in rural Kenya', in J.K. Nugent, B. Petrauskas \& T. Berry Brazelton (eds), The newborn as a
person: Enabling healthy infant development worldwide, pp. 85-97, John Wiley \& Sons.

Sutton, M., 2001, 'Policy research as ethnographic refusal: The case of women's literacy in Nepal', in M. Sutton \& B. Levinson (eds. Policy as practice: A sociocultural approach to the study of educational policy, Ablex Press, Westport, CT.

Swadener, B., Kabiru, M. \& Njenga, A., 1995, Does the village still raise the child? A collaborative study of changing child-rearing and community mobilization in Kenya, Kent State University, Kent, OH.

wa Thiong'o, N., 1986, Decolonizing the mind: The politics of language in African literature, Heinemann, New York.

Woodhead, M., 2006, 'Changing perspectives on early childhood: Theory, research and policy', International Journal of Equity and Innovation in Early Childhood 4(2), 1-43.

Zeitlin, M. \& Barry, O., 2008, Results of operational research by CRESP for plan international on the adaptation and administration of the Bayley III infant development test in Louga, Senegal Centre de Ressources pour l'Emergences Sociale le Participative, Dakar. 